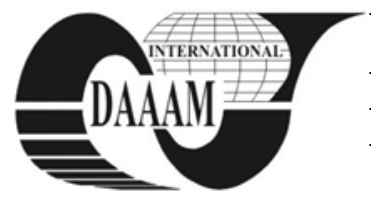

Annals of DAAAM for 2011 \& Proceedings of the 22nd International DAAAM Symposium, Volume 22, No. 1, ISSN 1726-9679 ISBN 978-3-901509-83-4, Editor B. Katalinic, Published by DAAAM International, Vienna, Austria, EU, 2011 Make Harmony between Technology and Nature, and Your Mind will Fly Free as a Bird

\title{
DETERMINATION OF INPUT PARAMETERS FOR THE DESIGN OF A ROTOR OF WIND-MILL MOTOR
}

\author{
SVRCEK, D[aniel]
}

\begin{abstract}
Axial rotor of wind-mill motor, e. g. wind power plant requires very sophisticated design of a rotor blade from the aerodynamic and strength aspects. The article deals with the determination of input parameters for a rotor of wind-mill motor with the high aerodynamic efficiency. Using onedimensional analysis, the recommended blade perimeter and revolutions of propeller for supposed performance of wind-mill motor are computed. Based on the definition of input parameters of rotor operation, the aerodynamic design of propeller blade with the optimal distribution of buoyancy forces-circulation on the blade span can be realized.

Key words: wind-mill motor, propeller diameter, propeller revolutions, rotor blade
\end{abstract}

\section{INTRODUCTION}

Aerodynamic design of a rotor blade of wind-mill motor with maximum efficiency in a given design point requires correct definition of input conditions and parameters. Following specified and more detailed computation depends on the design point and supposed total wind power of the rotor - propeller. The number of rotor blades and the blade depth can be then calculated for example using the circulation along the propeller blade (Brož\&Slavík, 1978, Hansen, 2008).

The main aim of this paper is to determine the input parameters for the design of a rotor of wind-mill motor applying simplified one-dimensional analysis of the air flow.

\section{1-DIMENSIONAL APPROACH TO THE ANALYSIS OF PROPELLER OPERATION}

Kinetic energy of air flow passing through the rotor of windmill motor is changing to the mechanical energy needed to the drive power of alternator for the production of electric energy. Only a part of energy is transformed to the mechanical work representing the total wind engine power $W$. The remaining part of energy converts to the energy of agitated air flow behind the rotor or it is flowing through the rotor unutilized. The pressure and velocity conditions in front of the rotor, behind the rotor and in the rotation axis of a propeller are illustrated in Fig. 1.

Using the Bernoulli equation (Taraba et al, 2004), the following relationships can be derived for single regions

$$
\begin{aligned}
& \frac{1}{2} v_{0}^{2}+\frac{p_{0}}{\rho}=\frac{1}{2} v_{s}^{2}+\frac{p_{1}}{\rho} \quad \text { in the region I-II } \\
& \frac{1}{2} v_{s}^{2}+\frac{p_{2}}{\rho}=\frac{1}{2} v_{1}^{2}+\frac{p_{0}}{\rho} \quad \text { in the region III-IV }
\end{aligned}
$$

in which $\rho$ is the air density, pressures and velocities are denoted according to Fig. 1.

Applying Eqs. (1) and (2), the pressure difference $\Delta p$ can be calculated as

$$
\Delta p=p_{1}-p_{2}=\frac{1}{2} \rho\left(v_{0}^{2}-v_{1}^{2}\right)
$$

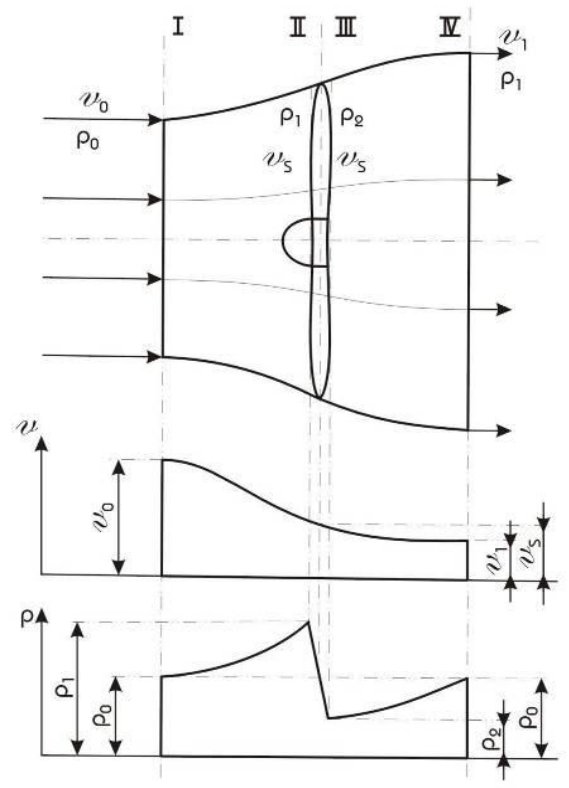

Fig. 1 Pressure and velocity profiles in wind-mill motor for 1Danalysis

\section{DETERMINATION OF THE APPROXIMATE POWER OF A ROTOR OF WIND-MILL MOTOR}

Rotor thrust $T$ can be calculated as a product of the propeller surface $S$ and the pressure difference in front of the propeller and behind the propeller

$$
T=S \Delta p=\pi R^{2} \frac{1}{2} \rho\left(v_{0}^{2}-v_{1}^{2}\right)
$$

Total power $W_{\mathrm{c}}$ which can be removed from the air flow with the velocity of $v_{\mathrm{s}}$, is expressed by the relationship

$$
W_{c}=T v_{s}=\pi R^{2} \frac{1}{2} \rho\left(v_{0}^{2}-v_{1}^{2}\right) v_{s}
$$

Denoting $v_{0}-v_{s}=a v_{0}$ where $a$ represents the axis (input) interference factor influencing the air flow in the rotation axis, $v_{s}=\left(v_{0}+v_{1}\right) / 2$ and substituting to the Eq. (5)

$$
W=\pi R^{2} \frac{1}{2} \rho 4 v_{0}^{3} a(1-a)^{2}
$$

The power ratio can be obtained by rearrangement the Eq. 6 in the form

$$
\frac{W}{\frac{1}{2} \rho \pi R^{2} v_{0}^{3}}=4 a(1-a)^{2}
$$

where the denominator represents the total kinetic energy involved in the rotor area. Then the ratio of the power which 
can be transformed to the necessary power of a wind rotor for the alternator drive to the total power of the air flow flowing through the rotor area is

$$
W / W_{c}=4 a(1-a)^{2}
$$

Using this approach, the determination of the maximum power removable from the energy passing through the rotor area is transformed to the finding of the maximum for the relationship $4 a(1-a)^{2}$.

The power ratio $W / W_{c}$ reaches the local maximum for the axis interference factor $a=1 / 3$ (Fig. 2). In the rotor rotation plane, the velocity of the input air flow $v_{0}$ decreases by $2 / 3$. Behind the rotor, the air flow velocity is $v_{0} / 3$. The points A, B, C (Fig. 2) represent the cases when

a) point A: the rotor does not reduce the air flow and therefore, it takes no power from the air flow,

b) point B: the maximum theoretically possible energy transfer from the input air flow to the effective energy, $W=0.5925 W_{\mathrm{c}}$,

c) point C: the rotor subscribes all energy and the air flow is stopped.

Of course, the described 1D air flow differs from the real air flow. The input air flow with the velocity of $v_{0}$ is not rotational but during the passing through the rotor it is turned in the direction of propeller rotation. By this rotation, the additional kinetic energy with the direction opposite to the propeller rotation is initiated. The total power $W_{\mathrm{c}}$ involved in unagitated flow passing through the rotor is comprised of $W_{\mathrm{c}}=W+W_{\mathrm{T}}+W_{\mathrm{R}}$ where $P=W_{\mathrm{T}}+W_{\mathrm{R}}$. Then

$$
W=W_{c}-P
$$

The power of wind-mill motor $W$ which is limited according to the total power $W_{\mathrm{c}}$ by the Betz limit $\left(0.5925 W_{\mathrm{c}}\right)$ is smaller due to the power decrease spent for translation $\left(W_{\mathrm{T}}\right)$ and rotation $\left(W_{\mathrm{R}}\right)$ air movement. That means that the efficiency of the transition of total power from the kinetic energy of the air passing through the rotor is lower than 50\%

$$
W \leq 0.5 W_{c}
$$

Taking into account mechanical losses and efficiency of the energy conversion from the mechanical to the electric by means of alternator, the above mentioned efficiency can be considered as good if the designed rotor has efficiency at the level of $45 \%$. Then the Eq. (6) can be rewritten to the form

$$
W=0.45 \pi R^{2} \frac{1}{2} \rho v_{0}^{3}
$$

The Eq. 11 can be sufficient for the initial design of a rotor of the wind-mill motor in the dependence on the input air flow velocity (Wilson\&Lissaman, 1974).

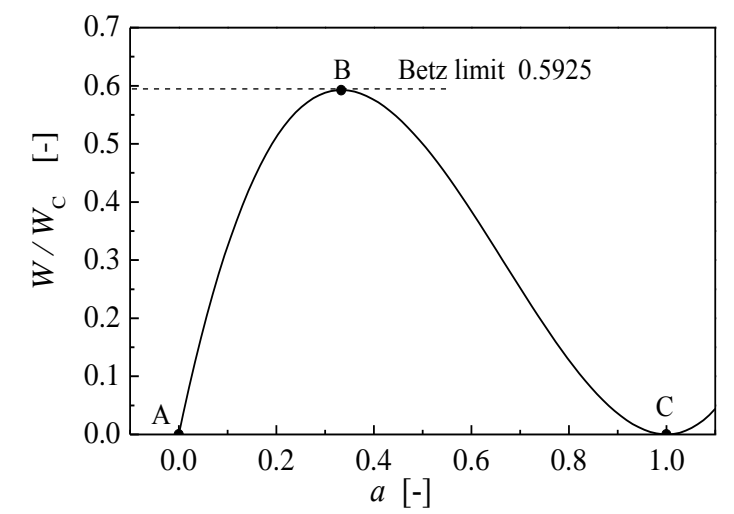

Fig. 2 Dependence of the power ratio on the axial interferential factor

\section{DIAMETER AND REVOLUTIONS OF A ROTOR OF WIND-MILL MOTOR}

The wind velocities $v_{0}$ are known from the meteoric conditions of the wind-mill realization. According to these conditions the total wind power $W$ is supposed. The perimeter of designed rotor can be then calculated as

$$
R=\sqrt{\frac{W}{0.866 v_{0}^{3}}}
$$

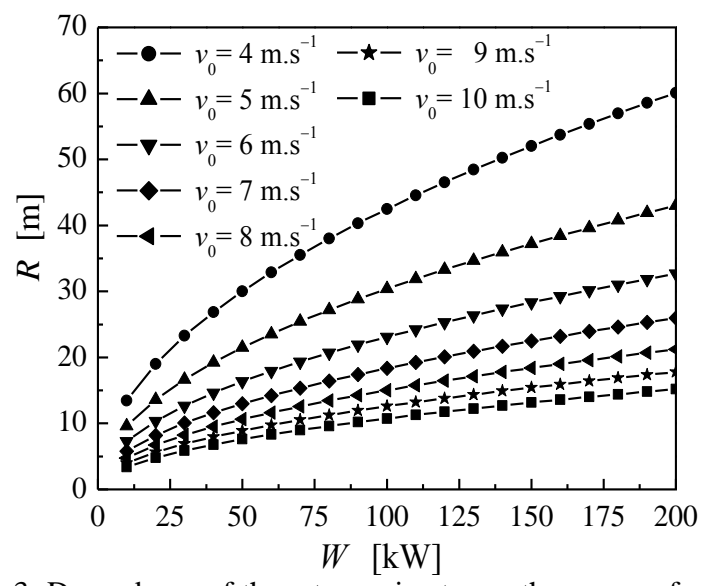

Fig. 3 Dependence of the rotor perimeter on the power of windmill motor for different input air velocities

To reduce the propeller noise, the propeller revolutions $n$ are select so as the tip of propeller blade does not exceed the peripheral velocity $u_{0}=\omega R=2 \pi n R=60 \mathrm{~m} \cdot \mathrm{s}^{-1}$ (Filakovský, 2007). From this condition, the revolutions can be calculated as

$$
n=\frac{u_{0}}{2 \pi R}
$$

\section{CONCLUSION}

According to the requirements to the design of a rotor of windmill motor for the given performance $W$ it is possible to define the following input parameters: velocity of input air flow $v_{0}$, propeller diameter $D$, propeller revolutions $n$ and the number of blades $z$ (Švrček, 2009). Taking into account harmonic excitation of oscillations, it is generally recommended to choose odd number of blades.

\section{ACKNOWLEDGEMENTS}

The research was supported by the VEGA MŠ SR and SAV within the project VEGA 1/0256/09.

\section{REFERENCES}

Brož, V. \& Slavík, S. (1978) Optimal distribution of circulation along the propeller blade. Report VZLÚ V-1348/79, Praha.

Filakovský, K. (2007) Design of a propeller blade for wind-mill motor. Transfer VZLÚ, Vol. 4, pp.16-22

Hansen, M. O. L. (2008) Aerodynamics of wind turbines, Earthscan, ISBN-13: 978-1-84407-438-9, London

Švrček, D. (2009) Aerodynamic Design of Propeller Blade with Optimum Circulation Layout. Proceedings of XXIII. MicroCAD International Scientific Conference, University of Miskolc, 2009. ISBN 978-963-661-878-0, pp. 43-50.

Taraba, B., Behúlová, M. \& Kraváriková, H. (2004) Mechanics of fluids. Thermomechanics. STU Bratislava, ISBN 80-2272041-0, Bratislava

Wilson, E. \& Lissaman, P. B. S. (1974) Applied aerodynamics of wind power machines. Oregon State University, Corvallis. 